\title{
Management of occupational back pain: the Sherbrooke model. Results of a pilot and feasibility study
}

Patrick Loisel, Pierre Durand, Lucien Abenhaim, Lise Gosselin, Robert Simard, Jean Turcotte, John M Esdaile

\begin{abstract}
Objectives-The aim was to combat occurrence of chronic occupational back pain.

Methods-A multidisciplinary model to manage back pain that includes both clinical and ergonomic approaches has been developed. Early detection, early clinical and ergonomic evaluations, and early active treatment make up the cornerstone of management. Detection of cases starts after four weeks of absence from work. An ergonomic intervention is implemented at six weeks. A medical specialist is involved at eight weeks. If return to work is not possible after 12 weeks, a functional recovery therapy followed by a therapeutic return to work is implemented. A multidisciplinary team decides if return to original or modified work is possible or if vocational rehabilitation is necessary. This model has been implemented by the investigators in the Sherbrooke (Quebec, Canada) area, and is presently being evaluated through a randomised trial in 31 industrial settlements (about 20000 workers). A cluster randomisation of industries and workers will allow separate testing of ergonomic and clinical interventions.
\end{abstract}

Results-One year after implementation, 31 of 35 of the eligible industrial sites participated in the study and 79 of 88 of the eligible workers affected by recent back pain had agreed to participate. Ergonomic and clinical interventions have been implemented as planned. Only three workers dropped out. Hence this global clinical and ergonomic management programme has been shown to be feasible in a general population.

Conclusion-A global management programme of back pain joining ergonomic and clinical intervention with a multidisciplinary approach has not been tested yet. Linking these two strategies in a same multidisciplinary team represents a systemic approach to this multifactorial ailment. During the first year of this trial we did not find any conflict between these two interventions from the employer's or worker's point of view.

(Occup Environ Med 1994;51:597-602)

Occupational back pain in industrialised countries is costly. In the United States direct costs have been estimated to vary between 20 and 55 billion dollars. ${ }^{1}$

Despite Nachemson's call for increased research on occupational back pain, ${ }^{2}$ both the number of patients with chronic back pain and the related costs continue to increase. ${ }^{3}$ Inadequate management of industrial back pain may be the major cause. ${ }^{3-6}$ For this reason, an innovative model of management of industrial back pain that extends the recommendations of the Quebec task force on spinal disorders in the workplace has been developed. ${ }^{4}$ The model, described in this paper, includes scheduled interventions for the workers sustaining back injuries and interventions at their worksites. It is presently being evaluated through a randomised trial in the area of Sherbrooke (Quebec, Canada).

\section{Rationale for the model}

Occupational episodes of back pain are often self limited. Seventy per cent of cases heal spontaneously in less than four weeks, and $95 \%$ in less than six months. ${ }^{7}$ The Quebec task force, ${ }^{4}$ reported that $75 \%$ of the total costs for occupational back pain in the province of Quebec (Canada) for the year 1981 arose from $7 \%$ of workers with chronic disease (absent from work for more than six months). Moreover, recurrence rate of episodes of back pain has been reported to be $36.3 \%$ over three years after a first episode. ${ }^{8}$ Others have reported similar figures. ${ }^{910}$

Because both the costs and disability arise from the chronic cases, the severity of back pain is usually graded more on the basis of symptom duration than on a specific pathological abnormality. ${ }^{341112}$ In fact, a precise diagnosis cannot be made in most chronic cases. ${ }^{341113}$ Even if a precise diagnosis can be made, treatment often remains aimed at relief of symptoms. Trial and error is often the guide. As a result, even treatments that have been proved ineffective continue to be used, and few treatments have been proved effective." Among treatments considered "probably effective" by the Quebec task force, some, such as transcutaneous electronic nerve stimulation ${ }^{14}{ }^{15}$ or facet joint blocks ${ }^{16}{ }^{17} 18$ have subsequently been shown to be no more effective than a placebo.

Both individual and occupational risk factors have been associated with back pain. Individual factors include previous episodes of back pain, ${ }^{13} 1920$ physical signs and symptoms, ${ }^{12}{ }^{19}$ coping difficulties, ${ }^{13}$ psychological distress, ${ }^{21}$ physical fitness, ${ }^{22}$ personal 
habits, ${ }^{23}$ and education level..$^{24}{ }^{25}$ Occupational problems include heavy work, ${ }^{26-28}$ specific types of work, ${ }^{26}$ jobsite arrangement and organisation, ${ }^{29}$ exposure to vibration, ${ }^{30}$ job satisfaction, ${ }^{31}$ and the adversarial nature of the workmen's compensation system..$^{32}{ }^{33}$ The role of these markers in an individual patient's disease is usually difficult to determine. Thus treating the $5-7 \%$ of chronic cases who do not heal by themselves is problematic. These difficulties explain the current management of chronic back pain, which seems to be disorganised, irrational, delayed, and often of a conflicting nature.

Disorganisation comes from the many different therapists (different medical and surgical specialists, acupuncturists, chiropractors, physiotherapists, and others) who may become involved over the course of a patient's illness. Various treatments are offered (for example, pills, herbs, injections, manipulations, physical therapies, surgery). Despite the availability of numerous different treatments from various therapists, no single approach has been proved more effective than the others. When back pain does not resolve, disability occurs, leading to prolonged absence from work. This has been named chronicity. ${ }^{31} 33$ So uncertainty in diagnosis leads to irrational treatments, and treatment by trial and error. Also, the compensation process is associated with chronicity. ${ }^{34}$ Compensation for occupational back pain is determined mainly by the regulations of workers' compensation boards sometimes involving legal actions. The regulations take precedence over the medical needs of the patient. ${ }^{32}$

\section{Description of the Sherbrooke model}

The challenge of treating chronic back pain has resulted in novel responses. The Quebec task force proposed a diagnostic grid and an organigram of desirable interventions to be implemented at specific times. The second included the advice of a medical specialist after seven weeks of absence from work, active treatment after eight weeks, and when no improvement occurred, early vocational rehabilitation. ${ }^{4}$ The usefulness of an ergonomic intervention was also suggested. Mayer et al have claimed that the multidisciplinary rehabilitation programmes that employ physical fitness and work conditioning programmes along with a cognitive-behavioural approach are effective. ${ }^{35}$ Wiesel showed that an appropriate management in collaboration with practising physicians was effective in a large industrial settlement, dramatically reducing the duration of absence from work and the number of surgical interventions. ${ }^{6}$ Recent studies have focused on the close relation between back pain and job satisfaction, ${ }^{31}{ }^{36}$ but practical solutions are not yet available. Although jobsite problems have been associated with back pain, no intervention studies aimed at increasing the return to work of injured workers before chronicity is established, have been performed.

The Sherbrooke model proposes to link these different approaches to provide integrated interventions, directed at both the worker and the jobsite (fig 1). A specialised multidisciplinary back pain clinic comprising a clinical and an ergonomic team, has early intervention to reduce chronicity as the main objective. Formal agreements have been negotiated between the clinic and industrial partners. To avoid unnecessary efforts and costs for the $70 \%$ of workers who return to work before four weeks, recruitment of workers in the back pain clinic begins at the fourth week of absence from work. Recurrences are taken into account by summing the days of absence from work due to back pain during the past year. Also all cases with one day or
Figure 1 Scheme of full intervention representative of the Sherbrooke model of back pain management. Return to work is possible at any time and will stop this process of intervention.
Step 0

Detection of cases at risk of chronicity

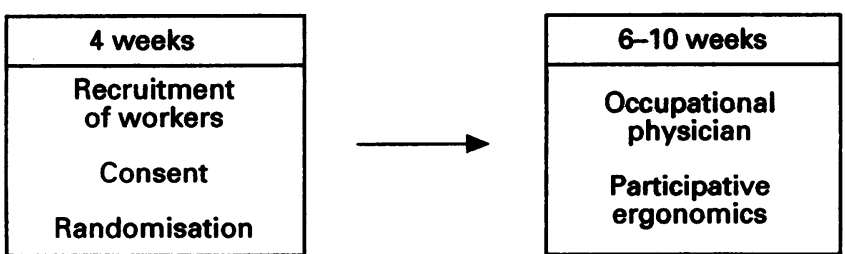

Step 1

Step 3

Early rehabilitation

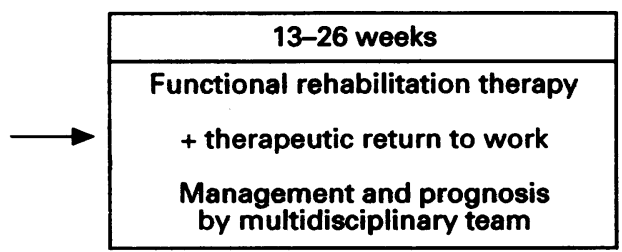

Step 2

Diagnostic and back school

8-12 weeks

Back pain specialist

Back school

End issue

Before 6 months

Return to previous work

Return to modified work

Vocational rehabilitation 
more of absence from work for back pain are declared to the research team. The industrial partners refer cases directly to the back pain clinic. Three successive management steps are used.

STEP 1

The first step is mainly occupational. On the sixth week of absence from work, an occupational physician examines the worker and an ergonomist visits the jobsite. The occupational physician is knowledgeable about back pain and the general characteristics of the different participating industrial partners. After examining the worker and obtaining worksite information, appropriate recommendations are submitted to the worker's general practitioner. Depending on the clinical state of the worker, the difficulty of the worker's tasks, and the availability of light duties, he may for instance, suggest ways to improve diagnosis or treatment, or propose a return to light or full duties. At the same time, an intervention called "participative ergonomics" is implemented at the jobsite with the collaboration of the injured worker. Participative ergonomics involves representatives of management and the unions who, with the help of the ergonomist of the back pain clinic, develop improvements in the work routine and evaluate job satisfaction. ${ }^{37} 38$ At that time an industrial partner is enrolled a two day orientation course is given to selected employees and management personnel, who will subsequently serve as the on site back pain advisory group for that company. The course includes teaching on occupational risk factors for back pain, ergonomic analysis, and the methods used in participative ergonomics. For each incident case these representatives meet with the injured worker, their supervisor, and the ergonomist. The ergonomic process takes the following steps. Firstly, the precise nature of the worker's tasks is clarified from the descriptions made separately by the employer and the worker. Then the work tasks are observed by the ergonomist, often in the presence of the injured worker. Data collected include work process, characteristics of other jobs linked to the tasks involved, features of equipment and design of the workplace, loads handled, precision, quality, quantities handled, pace of the job, postural requirements, and environmental characteristics of the jobsite. After these observations, an "ergonomic diagnosis" is made with regard to the back, and discussed with the injured worker, the supervisor, and the back pain group. Solutions are then discussed and proposed to the management. The employer can choose to disregard these recommendations. The ergonomist is made aware of the employer's decision, and this can influence the timing of the injured worker's return to work.

The role of the back pain clinic ergonomist is to help to find solutions to improve the worksite, as far as the back is concerned, and not to implement recommended modifications. This remains the employer's responsibility, but ergonomic problems are detected and proposed solutions are aimed at an earlier, safer, and stable return to work.

\section{STEP 2}

The second step focuses on diagnosis and instruction at a back school. If return to work has not occurred after seven weeks, the worker is examined by a medical specialist from the team to exclude a serious underlying condition (for example, malignancy). Any tests or consultations required are obtained. In the absence of a serious underlying condition that explains the back pain, the worker is directed to a back school. Back schools were recognised as effective for subacute back pain by the Quebec task force, but recently, doubt has been raised as to their value. ${ }^{39}$ The Sherbrooke back school is somewhat different from the usual. It is an activity that lasts for one hour every day for four weeks. Throughout the 20 hours of sessions, back education, coaching, and practice of appropriate exercises and counselling for daily life activities are provided.

\section{STEP 3}

If return to work has not occurred after the back school programme (after about 12 weeks of absence from work), we consider the back pain to be chronic. The third step of management is instituted. This step, named functional rehabilitation therapy, is a modified Mayer's intervention, ${ }^{35}$ including fitness development and conditioning for work with a cognitive behavioural approach. It is carried out by the multidisciplinary team of the back pain clinic. The functional rehabilitation therapy begins with a one week evaluation of physical fitness, functional capacity, and psychological state. New protocols have been developed for this evaluation. Physical fitness is evaluated by the physical educator of the team, through measurements of cardiorespiratory capacity, muscular strength and endurance, joint flexibility, and life habits. The occupational therapist performs a four day evaluation. This includes a specially developed set of isoinertial tests that reproduce common work situations, such as carrying loads at different heights or performing tasks in different postures. Time and weights are measured. Precise knowledge of the worker's normal tasks on the job are provided by the ergonomist. Psychological state is evaluated by a psychologist through questionnaires (MMPI, Beck) and a structured interview. A specific physical education, work hardening, and cognitive-behavioural support programme is then implemented for three to five weeks. It allows for a development of the global condition of the worker, and for improving specific skills and endurance required by the specific worker's tasks. More realistic expectations concerning the back condition and pain management skills are taught. This development of global functional capacities is followed by a progressive return to work, named therapeutic return to work. This involves alternating days of work and treatment. Work is progressively increased. 
Therapeutic return to work allows for a more complete recovery before returning to work on a full time basis, and helps to lessen the stress of return without recourse to specialised counselling. Therapeutic return to work is specifically designed for each individual case. The occupational therapist and the worker's supervisor agree on an appropriate and realistic progression of tasks.

Finally, taking into account the functional capacities of the worker during the functional rehabilitation therapy, if return to the original job seems unlikely to the multidisciplinary team (including the ergonomist), the worker is rapidly referred for a vocational rehabilitation programme. The purpose of the prompt referral is to avoid unnecessary, harmful, and costly delays. So, one of three courses is followed in the first six months in all cases: return to usual work, return to the usual job tasks but improved through the ergonomic intervention, or if not possible, because the back disease is not compatible with the job and because the job tasks cannot be improved through ergonomics, vocational rehabilitation.

VALIDATION OF THE MODEL

The proposed approach advocates the integrated management of subacute occupational back pain by an independent back pain clinic with the aim of preventing chronicity. The approach is innovative, especially in combining a clinical and ergonomic approach in a single integrated process. It has to be tested for its efficacy and cost effectiveness. A ran-

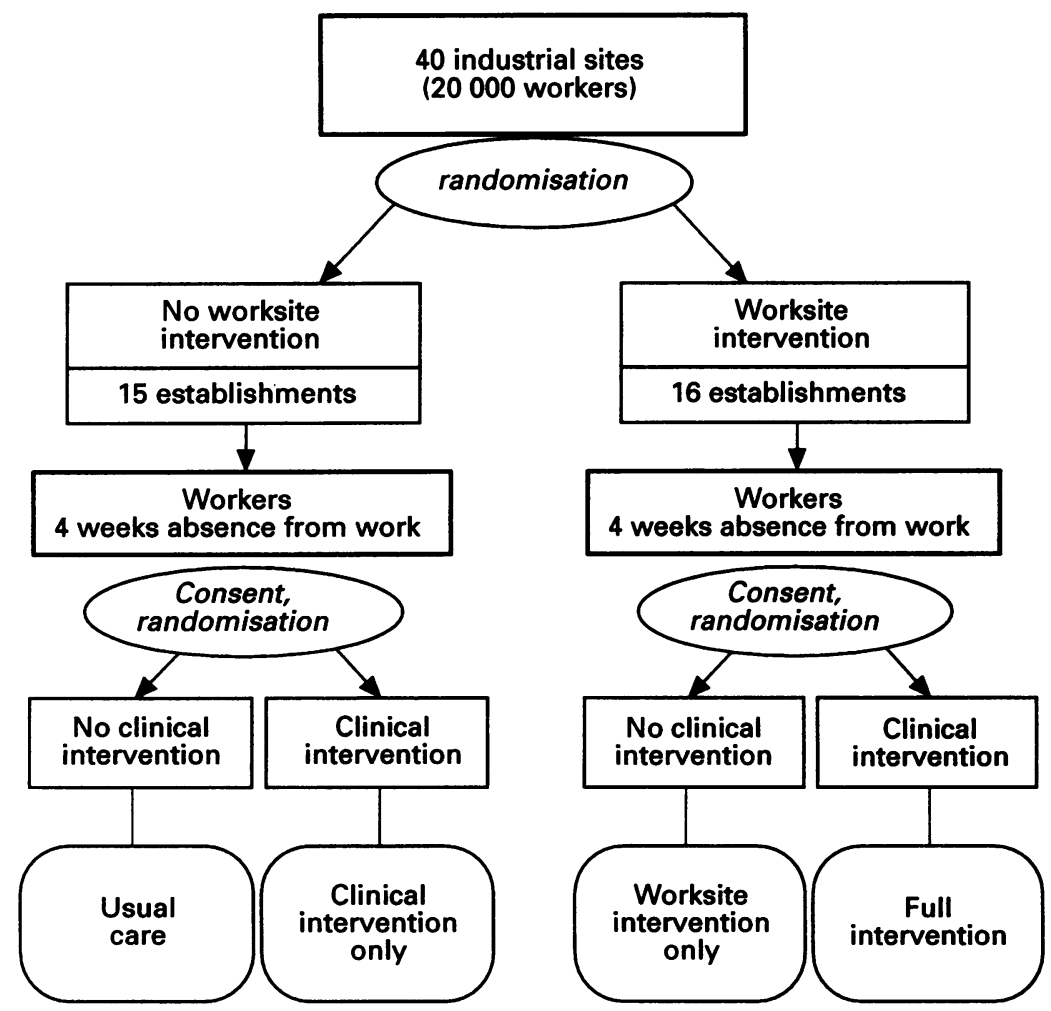

Figure 2 Cluster randomisation design used to compare the effectiveness of the worksite (ergonomic) intervention alone, the clinical intervention alone, or both worksite and clinical interventions combined, to standard care as provided by the worker's physician. Industrial partners have been randomised to receive the worksite intervention or not, to reduce contamination between cases for this intervention. domised trial, including both clinical and ergonomic components, has been initiated. The study population includes all the workers from the industries and government agencies with more than 175 workers within a radius of $30 \mathrm{~km}$ of the back pain clinic (located at the Sherbrooke University Hospital). A cluster randomisation of establishments and workers was made to allow the testing of multiple hypotheses. Specifically, the value of the ergonomic intervention alone, the clinical intervention alone, and the combined interventions in preventing chronicity will be evaluated (fig 2). Based on data from the worker's compensation board, 40 establishments met the inclusion criteria. Each of the 40 was first randomised to receive or not receive the ergonomic intervention. The establishments were randomised according to the number of employees $(<500$ or $\geqslant 500)$ and the industrial sector (services, hospitals, manufacturing). This approach ensured that the two intervention groups would be comparable in size and type of production. Also, given the different incidence rates of work accidents in the various industrial sectors, this would help in obtaining comparable rates in the two intervention groups. Each was then visited. The planned intervention was explained and proposed to the appropriate representatives of the management and the unions. After these visits, five establishments were excluded as more detailed inquiry showed that they failed to meet the inclusion criteria (all had $<175$ full time employees). Of the 35 eligible partners, four $(11 \%)$ refused to participate. The remaining 31 establishments signed a formal agreement of participation.

Workers with low back pain of four weeks in duration are referred to the back pain clinic. The purpose of the study is explained. Consenting subjects are randomised to the clinical intervention of the back pain clinic or to standard care arranged by their primary care physician (they have no access to the back pain clinic). This design enables the separate testing of hypotheses on the contribution of the ergonomic intervention and on the clinical intervention. As shown in fig 2, we obtain four different groups, one with minimal ergonomic and clinical interventions, one with maximal ergonomic and clinical interventions, and two groups with either one of the two types of interventions. Group identity of participating workers is unknown to the medical evaluators. The main dependent variable is the duration of absence from work, which should be shortened in the group with maximal interventions. The Kaplan-Meier method is used to obtain proportional curves for each group (survival curves). Sample size is estimated at 50 workers per group if the $a$ error is set at 0.05 and the $\beta$ error at 0.20 ; however, about 30 workers per group would probably suffice to verify the main hypothesis. ${ }^{40}$ Thus survival analysis and the Cox proportionate model will be used to verify the main hypothesis. No comparative analysis will be made before the end of the trial. The study received approval by the ethics committee of the Sherbrooke University Hospital (Centre 
Table Results of functional rehabilitation therapy for the 15 workers of the pilot study

\begin{tabular}{lllllll}
\hline Age & Type of work & Diagnosis & $\begin{array}{l}\text { Duration } \\
\text { of absence } \\
\text { (weeks) }\end{array}$ & $\begin{array}{l}\text { Duration } \\
\text { of FRT } \\
\text { (weeks) }\end{array}$ & $\begin{array}{l}\text { Duration } \\
\text { of TRW } \\
\text { (weeks) }\end{array}$ & $\begin{array}{l}\text { State after } \\
\text { 1 year }\end{array}$ \\
\hline 39 & Assistant cook & LBP & 59 & 4 & 8 & $\begin{array}{l}\text { Return to previous work } \\
\text { Return to previous work }\end{array}$ \\
$34^{\star}$ & Nurse & LBP & 49 & 9 & 4 & Return to previous work \\
33 & Assistant nurse & Lumbosciatic pain & 98 & 6 & 3 & Return to previous work \\
34 & Assistant nurse & Cervicodorsal pain & 55 & 7 & 5 & Return to previous work \\
38 & Welder & Lumbosciatic pain & 35 & 1 & 7 & Return to previous work \\
59 & Metal inspector & LBP & 31 & 6 & 4 & Return to previous work \\
25 & Mechanic & LBP & 22 & 2 & 0 & Return to previous work \\
48 & Press operator & LBP & 21 & 5 & 0 & Return to previous work \\
39 & Assistant nurse & Lumbosciatic pain & 31 & 3 & 7 & Return to previous work \\
37 & Secretary & Cervicodorsal pain & 36 & 10 & 7 & Vocational rehabilitation \\
58 & Mechanic & LBP & 32 & 5 & 4 & Vocational rehabilitation \\
29 & Assistant nurse & LBP & 90 & 13 & 0 & Vocational rehabilitation \\
44 & Packaging employee & LBP & 102 & 5 & 0 & Surgery \\
45 & Mechanic & Lumbosciatic pain & 28 & 2 & 0 & Surgery \\
31 & Assistant cook & Lumbosciatic pain & 28 & 3 & 3 &
\end{tabular}

${ }^{\star}$ Only one three day recurrence. $\mathrm{LBP}=$ Lower back pain; FRT $=$ functional rehabilitation therapy; TRW $=$ therapeutic return to work.

Hospitalier Universitaire de Sherbrooke, Sherbrooke, Québec, Canada).

RESULTS OF THE PILOT AND FEASIBILITY STUDY A trial such as that initiated required considerable preparation. Regional and provincial representatives of employers and unions were met to obtain their acceptance of the need for the study. Representatives of both management and unions of each potential industrial partner were met to explain the objectives of the study and the practical implications for the companies and the workers. Knowledge of the project was disseminated through information meetings for practising physicians in the study region, as well as posters, leaflets, and interviews in the local media.

Agreement with individual industrial partners was obtained in the summer and autumn 1991, and the enrolment of workers was started on September 2 1991. Thirty one establishments of various activities (industries, hospitals, and services), private and public, agreed and continue to participate after one year. By 15 September 1992, 88 eligible workers had been referred to the study. Seventy nine $(90 \%)$ agreed to participate. They have been randomised to the special clinical intervention at the back pain clinic or to standard care. Three (4\%) workers have dropped out. Ergonomic interventions have been performed in all the relevant worksites. The compliance of the industrial partners has generally been excellent, with participation of the representatives of the management and of the unions. Attending physicians have been compliant in applying the recommendations of the multidisciplinary team of the back pain clinic. The physicians consider that their patients have benefited from the prompt institution of specialised care.

Functional rehabilitation treatments and therapeutic return to work have been used in 15 patients who have gone on to prolonged back pain (more than six months duration), to ensure the quality and the feasibility of that process. The results of this pilot study (before the beginning of the randomised study) of combined functional rehabilitation therapy and therapeutic return to work have been satisfactory (table). Hence it has been applied to the randomised workers of the study.

Results of the efficacy study will not be available until both enrolment and follow up are completed.

\section{Discussion}

Disability and monetary costs arising from chronic back pain have motivated the design of our treatment model and its evaluation in a randomised trial. Based on a literature review, we believe that this model represents the first application of the clinical recommendations of the Quebec task force report. It combines an ergonomic intervention with advanced clinical management of workers with back pain for the first time.

The inability to predict which individual worker with low back pain will be among the $5 \%$ to $7 \%$ that go on to have sustained back pain justifies the early (after four weeks of disability) interventions used in our study. Whereas one could have relied on the Workers' Compensation Board to identify workers with back pain of four weeks duration, this is not permitted under Quebec law, even for a research study. Hence, we have developed consensus among both industries and unions for the need for the proposed study. This additional effort required is likely responsible for the ongoing complete participation of all the industrial partners and the high participation rate $(90 \%)$.

Ergonomic assessment is rarely used for determining the timing of return to work for workers with back pain. When an ergonomic intervention is offered, it is usually belated, when vocational rehabilitation is considered. In the model we are testing the ergonomic process is implemented early. Both the ergonomic assessment and the application of the resultant recommendations take time. A potential additional benefit is that jobsite improvements may improve work conditions for other workers doing the same job, and so prevent episodes of back pain in a more generalised way.

Functional rehabilitation therapy is usually not offered until chronicity has developed. In the Sherbrooke model this intervention is used early (after three months). We know that by three months, most of those still off work will become chronic cases. We expect earlier intervention with functional rehabilitation therapy will be beneficial.

Therapeutic return to work is a new con- 
cept, derived from assignment to light duties, but supervised by a clinical and ergonomic team. Implementation of therapeutic return to work requires the close collaboration of the occupational therapist, the worker, and the employer.

Ergonomic and clinical interventions are clearly very different strategies of intervention. The first is aimed at improving the workplace and the second at improving the functional capacities of the worker. Linking these two strategies in the same multidisciplinary team represents a systemic approach to this multifactorial ailment. During the first year of this trial we did not see any conflict between these two interventions from the employer's or from the worker's points of view. When functional rehabilitation therapy is necessary, the clinical team is helped by the advice of the ergonomist.

Ergonomics and functional rehabilitation therapy are costly interventions. The costs of income compensation, however, greatly exceed the costs of the treatments for back pain. ${ }^{9}$ For this reason, we anticipate that the costs incurred by these interventions will be less than the savings obtained by having participants return to work earlier.

Acceptance of the programme by the worker and his or her practising physician, and acceptance of the case as related to the occupation by the workers' compensation board, are necessary to allow participation of the worker. Even if the case is managed by the back pain clinic, the worker's family physician stays in charge and is continuously advised by the multidisciplinary team. In accordance with Quebec work regulations, it is mandatory that the physician chosen by the worker stays in charge and has the final decision on the treatment recommendations.

Most studies of occupational back pain have been implemented in a single industrial settlement with specific conditions, and the results may not be generalisable to other employers and workers. The present study involves most of the employers with more than 175 workers in a defined geographic area. Implementation of the Sherbrooke intervention study of occupational back pain has been made possible due to active collaboration between employers, unions, and the workers' compensation board.

Although the final results for efficacy and cost effectiveness are not yet available, the global clinical and ergonomic management programme has been shown to be feasible in a general population.

We gratefully acknowledge the careful help of Francine Lemay and Claude Alie, research assistants, and Sylvie Martineau, who typed the manuscript.

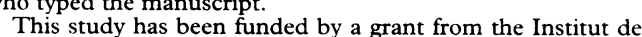

This study has been funded by a grant from the Institut de
Recherche en Santé et Sécurité du Travail du Québec Recherch
(IRSST).

1 Cats-Baril WL, Frymoyer JW. The economics of spinal disorder: The adult spine-principles and practice. New York: Raven Press 1991

2 Nachemson A. The lumbar spine, An orthopaedic challenge. Spine 1976;1:59-71.

3 Nachemson A. Newest knowledge of low back pain. A critical look. Clin Orthop 1992;279:8-20.

4 Spitzer WO, Leblanc FE, Dupuis $M$, et al. Scientific approach to the assessment and management of activityapproach to the assessment and management of activity-
related spinal disorders: a monograph for clinicians. Report of the Quebec Task Force on Spinal Disorders. Spine 1987;12:59.
5 Bigos SJ, Battie $M$. Acute care to prevent back disability Ten years of progress. Clin Orthop 1987;221:121-30.

6 Wiesel SW, Feffer HL, Rothman RH. Industrial low back pain-A prospective evaluation of a standardized diagnostic and treatment protocol. Spine 1984;9:199

7 Andersson GBJ, Pope MH, Frymoyer JW, Snook S. Epidemiology and cost. In: Pope MH, Frymoyer JW, Andersson GBJ, Chaffin DB, eds. Occupational low back pain: assessment, treatment and prevention. St Louis: pain: assessment, treatment and
Mosby year book, 1991:95-116.

8 Spengler DM, Bigos SJ, Martin NA, Zeh J, Fisher L, Nachemson A. Back injuries in industry: a retrospective study, I. Overview and cost analysis. Spine 1986;11: study,

9 Abenhaim L, Suissa S. Importance and economic burden of occupational back pain: a study of 2,500 cases representative of Quebec. f Occup Med 1987;29:670 - t.

10 Abenhaim L, Suissa S, Rossignol M. Risk of recurrence of occupational back pain over three year follow up. $\mathrm{Br} \mathrm{Y}$ Ind Med 1988;45:829-33.

11 Wood OHN, Baddley L. Epidemiology of back pain. In Jayson MIV, ed. The lumbar spine and back pain. 3rd ed. New York: Churchill Livingstone, 1987:1-15

12 Frymoyer JW. Predicting disability from low back pain Clin Orthop 1992;279:101-9.

13 Lancourt J, Kettelhut $M$. Predicting return to work for ower back pain patients receiving worker's compensation. Spine 1992;17:629-40.

14 Lehmann TR, Russell DW, Spratt KF, et al. Efficacy of electroacupuncture and TENS in the rehabilitation of chronic low back pain patients. Pain 1986;26:277-90.

15 Deyo RA, Walsh N, Martin D, Schoenfield L, Ramamurthy S. A controlled trial of transcutaneous electronic nerve stimulation (TENS) and exercise for chronic low back pain. N Engl f Med 1990;322:1627-34.

16 Jackson RP, Jacobs RR, Montesavo PX. Facet joint injection in low back pain: a prospective statistical study. Spine 1988;13:966-71.
Spine

17 Carette S, Marcoux S, Truchon R, Grondin C, Gagnon J, Allard Y, Latulippe M. A controlled trial of corticosteroid injections into facet joints for chronic low back pain. N Engl f Med 1991;325:14.

18 Jackson RP. The facet syndrome myth or reality? Clin Orthop 1992;279:110-21.

19 Frymoyer JW. Back pain and sciatica. N Engl f Med 1988 ; 318:291-300

20 Svensson HO, Andersson GBJ. Low back pain in 40 to 47 year old men: work history and work environment factors. Spine 1983;8:272-6.

21 Waddell G, Main CJ, Morris EW, DiPaola M, Gray ICM. Chronic low-back pain, psychologic distress, and illness behaviour. Spine 1984;9:209-13.

22 Cady LD Jr, Thomas PC, Kawarsky RJ. Program for increasing health and physical fitness of fire fighters. Occup Med 1985;27:110-4.

23 Deyo RA, Edward Bass J. Lifestyle and low back pain. The influence of smoking and obesity Spine 1989:14:501-6.

24 Vallfors B. Acute, subacute and chronic low back pain clinical symptoms, absenteeism and working environment. Scand f Rehabil Med 1985;11 (suppl):1-98.

25 Magora A, Taustein I. An investigation of the problem of sick leave in the patient suffering from low-back pain. sick leave in the patient suffering from low-back
Industrial Medicine and Surgery 1969;38:398-408.

26 Pope MH, Andersson GBJ. Chaffin DB. The workplace. In: Occupational low back pain: assessment, treatment and In: Occupational low back pain: assessment, treatment and

27 Nordin M, Frankel VH. Evaluation of the workplace an introduction. Clin Orthop 1987;221:85-8.

28 Troup JDG. Relation of lumbar spine disorders to heavy manual work and lifting. Lancet 1965;1:857-61.

29 Snook S. Approaches to the control of back pain in industry, job design, job placement and education training. Occup Med 1988;3:45-59.

30 Pope MH, Hansson TH. Vibration of the spine and low back pain. Clin Orthop 1992;279:49-59.

31 Bigos SJ, Battié MC, Fisher LD, Fordyce WE, Hansson TH, Nachemson AL, Spengler DM. A prospective study of work perceptions and psychosocial factors affecting the report of back injury. Spine 1990;16:1-6.

32 Greenough CG, Fraser RD. The effects of compensation on recovery from low back injury. Spine 1989;14 $947-55$

33 Trief $\mathrm{P}$, Stein N. Pending litigation and rehabilitation outcome of chronic back pain. Arch Phys Med Rehabil 1985;66:95-9.

34 Ontario Task Force on Vocational Rehabilitation: "An injury to one is an injury to all": towards dignity and independence for the injured worker. Report submitted to the Minister of Labour, 2 September, 1987.

35 Mayer TG, Gatchel RJ, Kishino N, Keeley J, Capra P, Mayer $\mathrm{H}$, et al. Objective assessment of spine function following industrial injury: a prospective study with comparison group and one-year follow-up. Spine 1985;10:482-93.

36 Bigos SJ, Spingler DM, Martin NA, et al. Back injuries in industry: a retrospective study. III Employee related factors. Spine 1986;111:252-6.

37 Straker LM. Work-associated back problems: collaborative solutions. Fournal of the Society of Occupational Medicine 1990;40:75-9.

38 Costa MJ, Patry L, Kuorinka J, Baril-Gingras G. Participatory ergonomics, the motor of an actionresearch in health safety. In: Queinnec Y, Daniellou F, ed. Project management: field studies. Paris: Taylor and Francis, 1991:1383-5.

39 Berwick DM, Budman S, Feldstein M. No clinical effect of back schools in an HMO a randomized prospective trial. Spine 1989;14:338-44.
tring

40 Lachin JM. Introduction to sample size determination and power analysis for clinical trials. Controlled clinical trials 1981;2:93-113. 